\title{
N-Methyl-D-Aspartate Antagonists Prevent Interaction of Binocular Maps in Xenopus Tectum
}

\author{
Warren J. Scherer and Susan B. Udin \\ Department of Physiology, State University of New York, Buffalo, New York 14214
}

\begin{abstract}
Glutamate receptors appear to play a key role in several forms of experience-dependent modification of both the strength of synapses and synaptic connectivity. In developing Xenopus frogs, the connections made by isthmotectal axons relaying visual input from the eye to the ipsilateral tectum are markedly influenced by the visual activity of contralateral retinotectal axons, and normal binocular visual input is necessary in order for the ipsilateral visuotectal map to come into register with the contralateral map. We have tested whether NMDA receptors play a role in establishment of the topographic matching of binocular maps during development. We have examined the effects of chronic treatment of tectum with either the receptor agonist NMDA or the antagonists APV or CPP applied throughout early postmetamorphic life using subpial implants of drug-impregnated elvax. Both antagonists blocked the matching of the ipsilateral map to the contralateral map, while NMDA permitted such matching. Our data therefore indicate that NMDA receptors are involved in the experience-dependent establishment of matching binocular maps during development.
\end{abstract}

Visual experience dramatically influences the processes which bring the map from the ipsilateral eye to the tectum into register with the map from the contralateral eye during the development of the frog Xenopus laevis (Gaze et al., 1970; Udin and Keating, 1981; for review, see Udin, 1985). In Xenopus embryos, the topographic retinotectal projection from the contralateral eye develops in the first few days after fertilization (Gaze et al., 1979; O'Rourke and Fraser, 1986), and visual deprivation does not interfere with the organization of that contralateral map (Keating et al., 1986). In contrast, the ipsilateral eye's map develops many weeks later, during metamorphosis (Beazley et al., 1972; Grant and Keating, 1986). Nonvisual cues initially establish a rough ipsilateral map (Keating and Kennard, 1987), but binocular activity is essential for refining the map and for bringing the 2 eyes' maps into alignment (Keating and Feldman, 1975). Moreover, if one eye is experimentally misaligned in the orbit, the resulting mismatch in visual activity from the 2 eyes induces the ipsilateral map to reorient on the tectum until it matches the contralateral map (Udin and Keating, 1981), and the duplication of contralateral maps resulting from a surgically

\footnotetext{
Received Mar. 29, 1989; revised May 30, 1989; accepted June 7, 1989.

We thank Mark Fisher for his technical assistance. Hollis Cline and Martha Constantine-Paton for their generous instruction in the preparation of elvax implants, and Mark Fisher and Donald Faber for their comments on the manuscript. This work was supported by US Public Health Service Grant EY-03470 to S.B.U.

Correspondence should be addressed to Dr. Susan B. Udin, 327 Cary Hall, SUNY, Buffalo, NY 14214.

Copyright $@ 1989$ Society for Neuroscience $0270-6474 / 89 / 113837-07 \$ 02.00 / 0$
}

constructed compound eye causes corresponding abnormalities in the ipsilateral map from a normal eye (Gaze et al., 1970). These experimental results imply that correlation of activity from the 2 eyes provides the cues which bring the ipsilateral eye's map into register with the contralateral eye's map and that these activity-mediated processes can override other organizing factors such as chemoaffinity cues (Sperry, 1944).

The pathway which brings visual input to the tectum from the ipsilateral eye is indirect, involving a relay through a midbrain structure, the nucleus isthmi (Fig. 1) (Glasser and Ingle, 1978; Gruberg and Udin, 1978; Grobstein and Comer, 1983). During normal development, isthmotectal axons make and break connections in a process which brings the terminals of an isthmotectal axon with a given receptive field location (a in Fig. 1) to the region of the tectum which receives retinotectal input for the same receptive field location (Udin, 1989). We hypothesize that that process involves activity-dependent mechanisms: the correlated activity from the 2 eyes at each tectal location will stabilize the appropriate isthmotectal terminals through retinal activation of NMDA receptors on tectal cell dendrites. [Retinotectal axons, but not isthmotectal axons, appear to be glutamatergic (Roberts and Yates, 1976; Ricciuti and Gruberg, 1985; Desan et al., 1987; Debski and Constantine-Paton, 1988).] During development, isthmotectal branches which terminate at locations with noncorresponding contralateral activity are not retained, and new branches continue to form, perhaps at random, at least until matching of the maps is attained (Fig. $2 A$ ). If one of the eyes is experimentally rotated during larval life, then the branching patterns of the isthmotectal axons change (Fig. $2 B$ ) (Udin, 1983). The new connections bring the ipsilateral map into topographic register with the rotated retinotectal map (Udin and Keating, 1981).

NMDA receptors have unusual characteristics which make them of special interest with regard to activity-dependent mechanisms. The classical "Hebbian" model for such processes postulates that sets of synapses onto a dendrite are strengthened or stabilized when their activity is sufficiently well correlated temporally to evoke postsynaptic firing (Hebb, 1949). Other variations of this model simply require that the active synapses evoke some threshold amount of postsynaptic depolarization, which would, in turn, trigger some biochemical and/or structural changes in the recently active synaptic complex. Thus, a Hebbian system could utilize a receptor which would only open when some minimal number of excitatory synapses was active within a short period of time. The NMDA-type glutamate receptor is an ideal candidate for such a receptor because its channel is blocked by magnesium ions when the local membrane environment is near to resting potential (Nowak et al., 1984), but when enough net excitatory input is present, the resulting 


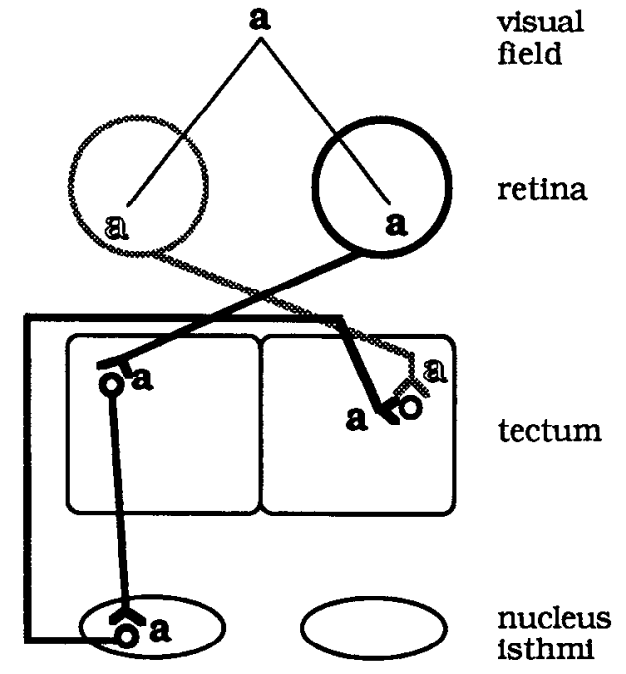

Figure 1. Wiring diagram of the normal circuitry underlying binocular input to the right lobe of the tectum. Symmetrical connections, not shown, bring binocular input to the left lobe.

depolarization expels the magnesium ion and allows glutamate to open the channel. Thus, this channel would open when enough excitatory synapses were active within a short time span. Another significant aspect of the NMDA-type glutamate channel is that it allows calcium to flow into the postsynaptic cell (MacDermott et al., 1986; Connor et al., 1988). This calcium could then somehow "prime" the dendrite for some tens of milliseconds so that a concurrently active isthmotectal synapse onto that dendrite would become stabilized. This type of mechanism has been implicated in mediating activity-dependent changes in synaptic strength in the adult hippocampus (Collingridge et al., 1983; Harris et al., 1984; Collingridge and Bliss, 1987) and in the developing visual cortex (Kleinschmidt et al., 1987).

In order to test whether NMDA receptors play a comparable role in the activity-dependent stabilization of developing isthmotectal terminals, we have chronically applied NMDA or NMDA antagonists to the tectum during development in frogs which had had one eye rotated during midlarval life. Our electrophysiological mapping data demonstrate that NMDA antagonists interfere with the visually dependent process which brings binocular maps into alignment during development.

These results have becn presented in abstract form (Scherer and Udin, 1988).

\section{Materials and Methods}

Tadpoles of stages 55-60 (Nieuwkoop and Faber, 1967) were anesthetized by immersion in MS-222 (tricaine methanesulfonate, 1:4000, Sigma). The left extraocular muscles were cut, and the left eye was rotated approximately $90^{\circ}$ clockwise about the optic nerve. Eye rotations were performed at these stages because the tadpoles are transparent, and the operations are therefore simple to perform without damaging the optic nerve. Partial derotation occurred in some of the tadpoles. Within 1 week of metamorphic climax, the animal was reanesthetized and the tectum was exposed; a slice of elvax (Cline et al., 1987), $30 \mu \mathrm{m}$ thick and approximately $1 \mathrm{~mm}^{2}$ in area, impregnated with $0.1 \mathrm{mM}$ NMDA, $0.1 \mathrm{mM}$ DL-2-amino-5-phosphonovaleric acid (APV), $0.1 \mathrm{mM} 3-(( \pm)-2-$ carboxypiperazin-4-yl)-propyl-1-phosphonic acid (CPP) or 10\% Holtfreter's solution was placed subpially on the right tectal lobe. The implantations were performed after metamorphosis rather than during tadpole stages because the larger size of the postmetamorphic tecta facilitates the surgery and improves survival rate compared with similar operations in tadpoles. During the interval between the eye rotation and
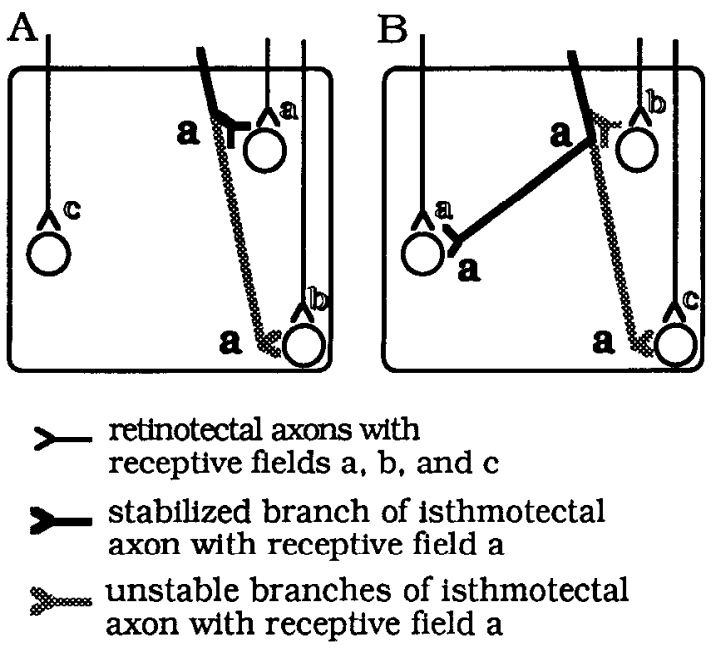

Figure 2. Schematic views of mechanism by which binocular projections come into register during development. The topography of the contralateral projection is established during midlarval life. In late larval stages, each axon of the ipsilateral projection distributes its branches along the rostrocaudal tectal axis. In $A$, the isthmotectal axon with receptive field a contacts 2 tectal cells. The branch onto the tectal cell which also receives contralateral input corresponding to field a will be retained (solid line), while the branch onto the tectal cell with contralateral input from field b will retract (stippled line). This ipsilateral axon does not normally contact the third cell. In $B$, the eye rotation has altered the receptive fields of the retinotectal axons. None of the original branches of the isthmotectal axon is stabilized; new branches form and establish connections with the tectal cell driven by the retinotectal axon which now sees position a. Bold letters label isthmotectal axons and outline letters label retinotectal axons.

the elvax implantation, no measurable rearrangement of the isthmotectal projection is likely to have occurred (Grant, 1982).

After 3 months, the froglet was reanesthetized and prepared for electrophysiological recording. This interval of time was chosen because previous studies indicated that readjustment of the ipsilateral maps is usually complete by this age (Grant, 1982). The animal was positioned with the left eye centered in an aluminum hemisphere (radius, $21 \mathrm{~cm}$ ), and metal electrodes were used for recording the activity of retinotectal and isthmotectal terminal arbors (Dowben and Rose, 1953). The electrode was positioned according to a grid superimposed on a photograph of the tectum, and locations of visual receptive fields were determined by moving a $7^{\circ} \times 5^{\circ}$ black rectangle on the inner surface of the hemisphere. The electrodes were positioned in the superficial neuropil of the tectum, where few cell bodies are located. Our maps reflect presynaptic activity rather than the postsynaptic activity of binocular tectal cells. We recorded both single- and multiunit receptive fields. Single-unit receptive field sizes of ipsilateral units are typically $5^{\circ}-10^{\circ}$ in diameter, while multiunit fields are generally $10^{\circ}-20^{\circ}$ (Keating and Feldman, 1975). In some cases in each experimental group, the entire contralateral map was recorded first; the left optic nerve was then cut, and the ipsilateral map was recorded at the same electrode positions as were used for the contralateral map. In other animals, the 2 maps were recorded in an interleaved fashion, by recording the contralateral field at a given tectal locus when the right eye was covered and then switching the occluder to the left eye in order to record the ipsilateral field to the same tectal location. During most recording sessions, some of the ipsilateral field locations were determined by the experimenter, who did not know the location of the corresponding contralateral field recorded from the same tectal site.

In order to examine whether the implants had damaged the tectum, we removed 7 brains, fixed them with $2.5 \%$ glutaraldehyde in $0.1 \mathrm{M}$ phosphate buffer, sectioned them, and stained them with cresyl violet. In 5 other frogs, we labeled the retinotectal projection from the left eye with HRP at the conclusion of the recording session. A pledget of gelfoam impregnated with HRP was placed on the cut optic nerve. After $3 \mathrm{~d}$ survival, the animal was reanesthetized and the tecta were reacted as whole mounts (Udin and Fisher, 1983). 
a. NORMAL

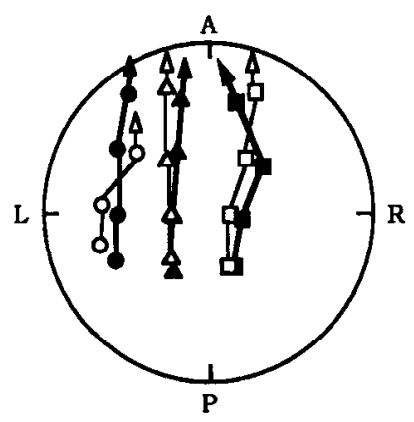

b. CONTROL ROTATED

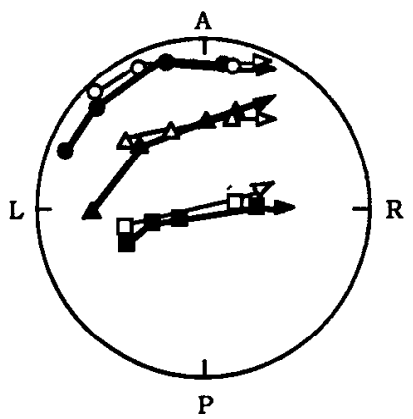

f. APV

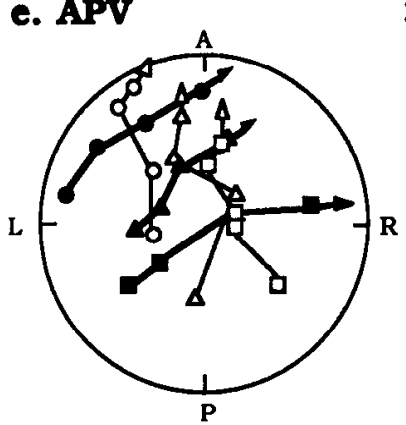

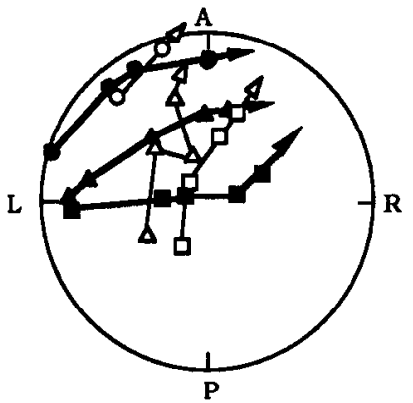

c. NMDA

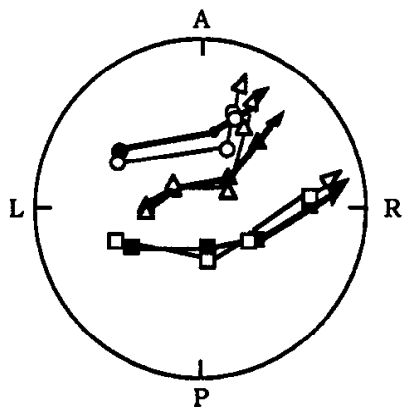

g. APV

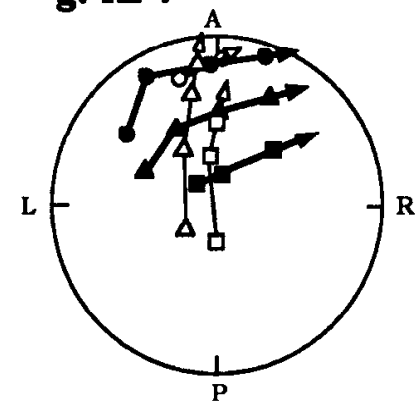

d. TECTUM

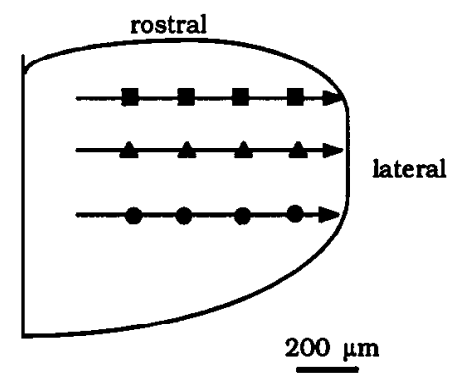

h. CPP

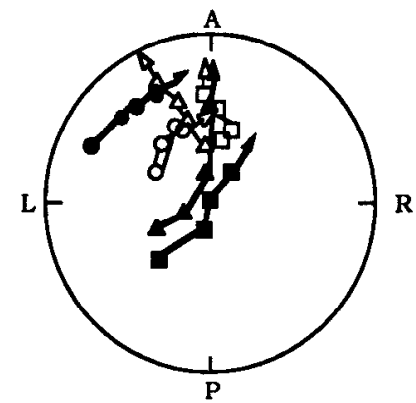

Figure 3. Electrophysiological maps $(a-c, e-h)$ of the receptive fields recorded at selected sites in the right tectal lobe $(d)$. Each point represents the center of a visual receptive field from the contralateral eye (closed symbols) or the ipsilateral eye (open symbols). $a$, Normal frog; $b, \sim 90^{\circ}$ rotation of left eye, control elvax implant; $c, \sim 80^{\circ}$ rotation of left eye, NMDA-impregnated implant; $d$, representation of dorsal view of right lobe of tectum; rostral is upward. $e-g$, APV-impregnated implants. $75^{\circ}-90^{\circ}$ rotation of left eye. $h, \sim 60^{\circ}$ rotation of left eye, CPP-impregnated implant. $A$, anterior visual field; $P$, posterior visual field; $R$, right visual field; $L$, left visual field.

\section{Results}

Figure $3 a$ illustrates a representative topographic map of visual space in a normal animal. The receptive field centers recorded from the terminals of retinotectal and isthmotectal axons progress in an orderly fashion from posterior to anterior visual field as one moves from medial to lateral tectum and from right to left as one moves from rostral to caudal tectum (Fig. 3d). For a given tectal location, the receptive fields of the 2 eyes coincide.

Surgically rotating the left eye (and thus rotating the contralateral map on the right tectal lobe) by $90^{\circ}$ in a tadpole results in the development of a rotated, but congruent, ipsilateral map, as the isthmotectal axons alter their trajectories to bring the ipsilateral projection into alignment with contralateral topography during early postmetamorphic life (Udin and Keating, 1981). An example of this plasticity is shown in Figure $3 b$ for a control animal whose tectum had a drug-free elvax implant placed subpially. A similar result was observed with 5 animals that had received an eye rotation and elvax implant containing $100 \mu \mathrm{M}$ NMDA; the adult maps were rotated, as shown in Figure $3 c$. Figure $3 c$ also shows the maximum amount of distortion of the 2 maps which we have found in the NMDA maps (right anterior fields). The distortion probably is a reflection of a disturbance of the rotated left eye consequent to rotation. Despite this abnormality, the ipsilateral receptive field locations are congruent with the contralateral receptive field locations. As indicated in our quantitative assessment of these maps, discussed below, the NMDA maps as a whole were indistinguishable from the control rotated maps.

In contrast, chronic treatment with $100 \mu \mathrm{M}$ APV prevented the realignment of the ipsilateral projection (Fig. 3, $e-g$ ). In these 7 cases, the map from the contralateral eye was rotated, but that from the ipsilateral eye was not; it resembled a normally oriented map, although some order was lost. This result indicates that APV may block an activity-dependent mechanism that is responsible for realignment of the right eye's projection in response to rotation of the left eye.

These results led us to ask whether APV's effect might be due to a complete block of retinotectal transmission, rather than a selective block of just the NMDA-type glutamate receptor. The possibility that APV causes a complete block of synaptic transmission was tested by recording responses "downstream" from the tectum in early postmetamorphic froglets after a 2 week exposure to APV. This duration of exposure was chosen for 2 reasons. First, we felt that 2 weeks would probably be sufficient time for any chronic changes such as up-regulation of NMDA receptors to have occurred. Second, we wished to assess the likely state of the system during a part of the critical period when major changes in the maps generally take place following early eye rotation (Grant, 1982). We monitored the activity which is relayed via the tectoisthmotectal pathway from the APV-treated tectal lobe to the opposite lobe (Fig. 4). In othcr words, we recorded left eye input to the superficial layers of the left tectal lobe, the only pathway for this input being via the treated right lobe. The right optic nerve was cut. Visually evoked responses from the left eye to the left tectum were clearly present despite the presence of APV in the opposite lobe (data not shown). In fact, our impression is that the responses were distinctly more vigorous than normal. (See also Debski et al., 1989, for data from Rana pipiens consistent with this observation.) 


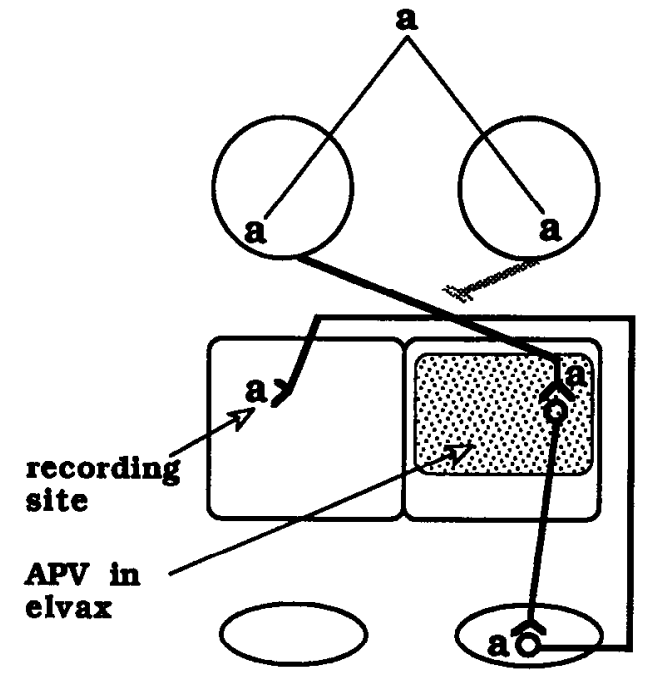

Figure 4. Schematic diagram showing that recordings madc from ipsilateral visual units in the left tectal lobe can reveal whether APV blocks retinotectal transmission through the right tectal lobe.

We are currently assessing this possibility using quantitative tests.

The effects of CPP treatment are shown in Figure $3 h$. The maps were out of register, and the map of the ipsilateral projection encompassed only about $40 \%$ of the normal visual field. A small degree of approximately normal mediolateral order was present in the condensed ipsilateral maps, which corresponded to the more central part of the field. The contralateral map, although appropriately rotated and orderly in most cases, also lacked some of the peripheral regions of the field.

Pooled data for all of the frogs in each group are presented in Figure 5, which shows the azimuth (left-right position) of each receptive field center plotted against the mediolateral tectal position at which it was recorded. The data plotted in Figure 5, $a, b$, indicate that the contralateral and ipsilateral maps are closely aligned for both control and NMDA-treated groups (same azimuth for both ipsilateral and contralateral fields recorded at a given position). Treatment with APV had no effect on the order or orientation of the contralateral map (Fig. $5 c$ ), but the drug prevented the ipsilateral fields from coming into register with the contralateral fields. The ipsilateral units were oriented as if there had been no rotation of either eye. (Compare also the ipsilateral maps in Fig. $3 e-g$ with $a$.) The pooled data for CPP-treated animals are shown in Figure $5 d$. The orientation of the contralateral positions reflects the rotation of the left eye, although the data points exhibit slightly more scatter than was shown by the contralateral units in the controls and the other experimental groups. The ipsilateral data points for the CPPtreated animals represent extremely disordered visual maps, and the points are located in only part of the normal ipsilateral field. The correlation coefficients of the ipsilateral units in the APVand CPP-treated tecta were not statistically different from 0 , the expected value for unrotated maps (Table 1).

In order to determine whether the implants had damaged the retinotectal projection, HRP was applied to the left optic nerve immediately following the electrophysiological mapping in 3 frogs with control elvax implants and in 2 frogs with APV implants. After $3 \mathrm{~d}$ survival, the label was found to be distributed
Table 1. Correlation coefficients of regression lines of receptive field azimuths

\begin{tabular}{llllll} 
Series & $n$ & Eye & $r$ & $N$ & $P$ \\
\hline Control & 5 & Contralateral & 0.832 & 63 & $<0.002$ \\
& & Ipsilateral & 0.780 & 39 & $<0.002$ \\
NMDA & 5 & Contralateral & 0.815 & 28 & $<0.002$ \\
& & Ipsilateral & 0.787 & 28 & $<0.002$ \\
APV & \multirow{2}{*}{7} & Contralateral & 0.803 & 84 & $<0.002$ \\
& & Ipsilateral & -0.045 & 80 & $>0.10$ \\
CPP & \multirow{2}{*}{5} & Contralateral & 0.432 & 54 & $<0.002$ \\
& & Ipsilateral & -0.164 & 48 & $>0.10$
\end{tabular}

$n=$ number of frogs in each group. $N=$ number of penetrations in which receptive fields were recorded. $P$, Pearson's product moment correlation 2-tailed test of probability that regression coefficient, $r$, is significantly different from zero.

normally in the right tectal lobe. In addition, 3 control and 4 APV-treated tecta were sectioned and stained with cresyl violet; localized damage was visible in one of the control brains, but the other brains appeared grossly normal.

\section{Discussion}

We have found that chronic application of the NMDA receptor antagonists APV or CPP prevents ipsilateral maps from coming into register with rotated contralateral maps in developing Xenopus. In contrast, NMDA permits the expected interaction of the 2 maps. Thus, we conclude that NMDA receptors play a role in activity-dependent alignment of binocular maps in Xenopus tectum.

The possibility that NMDA receptors influence the development of orderly projections in the amphibian optic tectum was first examined by studies in surgically produced 3-eyed frogs (Cline et al., 1987). In such animals, optic fibers from the supernumerary eye compete for tectal space with fibers from the normal eyes. The result of this competition is the formation of rostrocaudally oriented eye-specific tectal stripes. Chronic treatment with APV desegregates eye-specific stripes, while chronic NMDA treatment produces stripes with sharper borders and fewer branches. These results imply that the activity-dependent aspect of retinotectal map formation involves the activation of NMDA receptors. Our results extend these results by demonstrating that NMDA antagonists also perturb the processes which underlie the matching alignment of binocular maps during development. These results are consistent with the hypothesis that the release of glutamate by retinotectal axons and the consequent activation of NMDA receptors are essential steps in the development of orderly binocular maps in the tectum.

However, the processes which mediate activity-dependent matching of binocular maps must differ in some respects from the processes which underlie activity-dependent segregation of retinotectal terminals in 3-eyed frogs. In the latter case, the interactions involve 2 sets of basically identical afferents, namely, the retinotectal axons from the host and the retinotcctal axons from the supernumerary eye. For binocular matching, however, the interactions involve 2 distinct types of afferents, the retinotectal fibers and the crossed isthmotectal fibers. Another difference between these 2 systems is that of timing: visually elicited isthmotectal activity arrives about $30 \mathrm{msec}$ later than retinotectal activity, with the delay due to conduction across at least 2 more synapses and additional axonal distance. Moreover, isthmotectal axons probably release $\mathrm{ACh}$ rather than glutamate and 

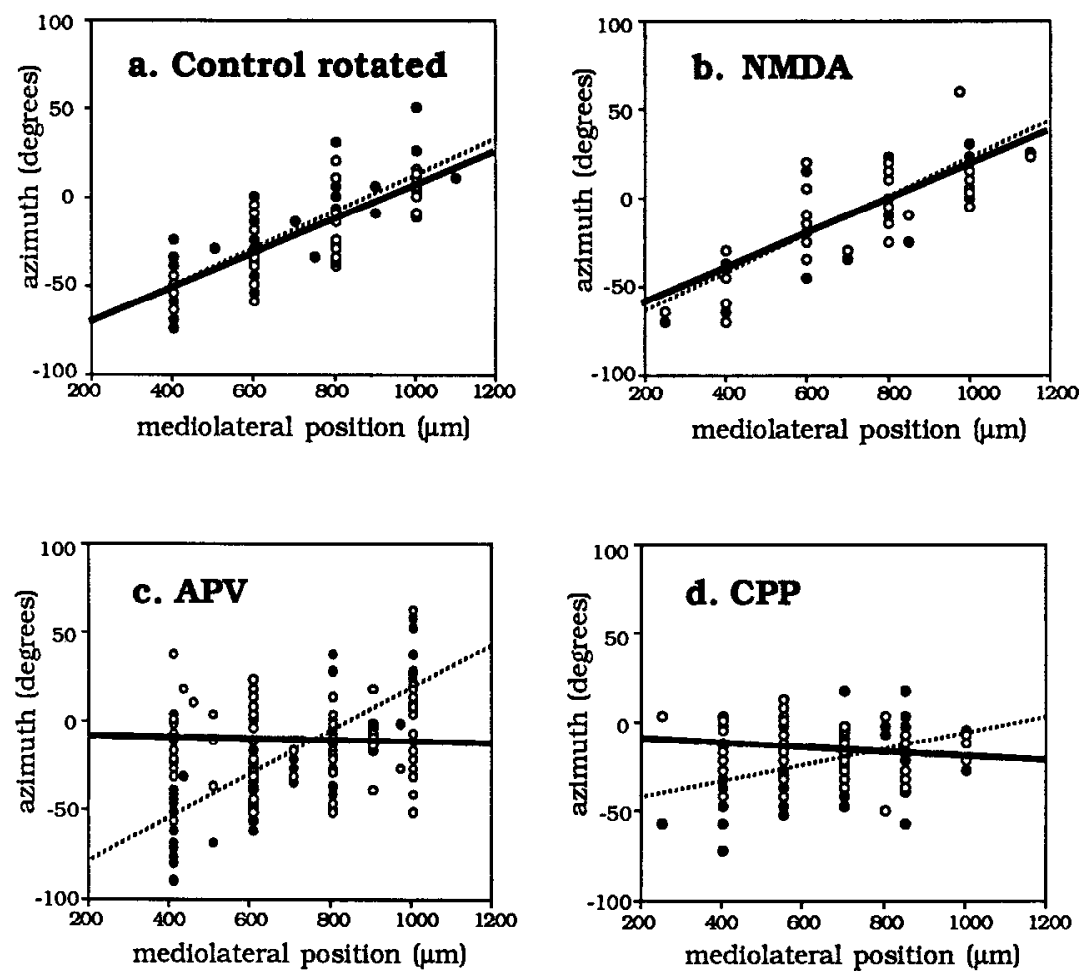

Figure 5. Pooled data showing the relationship between the azimuth of contralateral (closed symbols, dashed lines), and ipsilateral (open symbols, heavy lines) visual receptive field centers and mediolateral distance from tectal midline for $(a)$ control, $(b)$ NMDA-treated, (c) APV-treated, and (d) CPP-treated frogs. Lines are fitted by linear regression.

thus are unlikely to stimulate NMDA receptors directly (Ricciuti and Gruberg, 1985; Desan et al., 1987).

We take these factors into account in the following model. A visual stimulus evokes retinotectal activity in the contralateral tectum, and this activity is sufficient to depolarize tectal cells to the point where magnesium ions are expelled from NMDA receptors on the dendritic membranes. The NMDA receptor channels open and allow an influx of calcium, which in turn "primes" the tectal cell dendrite for a period of about $100 \mathrm{msec}$. The visual stimulus also evokes ipsilateral eye input to the tectum. The activated isthmotectal terminals which are in contact with the "primed" dendrites will become stabilized via some sort of feedback from the dendrite. Any other activated terminals which have grown to inappropriate regions and have contacted unprimed dendrites will be destabilized. Thus, over time, each isthmotectal terminal arbor will gradually become focused in the tectal region which receives input from retinotectal terminals with matching receptive field locations.

This model accounts for our finding that NMDA receptor antagonists prevent the ipsilateral maps from matching up with the contralateral maps but does not explain why the ipsilateral maps nevertheless display considerable internal order and are aligned as if there had been no eye rotation. We suggest that isthmotectal axons are able to use chemoaffinity cues to establish a rough "normal" order when they are deprived of the ability to take their topographic cues from contralateral retinotcctal axons. Support for this view comes from anatomical studies of the trajectories of developing isthmotectal axons (Udin, 1989). When growing isthmotectal axons approach the tectum from the optic tract, they spread out in an orderly way along the rostral border of the tectum. Each axon is guided to approximately the "correct" mediolateral position, i.e., a position which it will maintain as the normal ipsilateral map develops. Since this orderly arrangement begins when the 2 eyes face laterally in the head, with negligible binocular overlap of their fields, initial mediolateral order probably develops under the guidance of chemoaffinity cues. The mediolateral order we see in the ipsilateral maps of APV-treated tecta may reflect a persistence of this early mediolateral topography. In contrast, the isthmotectal axons do not initially display any order along the rostrocaudal axis (Udin, 1989). Instead, most of them extend straight caudally, often reaching the caudal end of the tectum without extending more than a few short side branchlets. An orderly pattern of arborization only develops later, as the eyes shift position in the head and establish a region of binocular overlap. We perform the eye rotations prior to this stage, and thus the rostrocaudal order we see in the ipsilateral maps of the APVtreated tecta is not a simple reflection of some preexisting order. We speculate that it is the result of some relatively weak influence of rostrocaudally distributed chemoaffinity cues, which provide a weaker organizing force than the cues which bring about mediolateral order.

The lack of apparent effect of NMDA on binocular mapping during development raises several issues. Does chronic NMDA treatment cause the tectal cells' NMDA receptors to be more likely than normal to open and to trigger the events which stabilize ipsilateral units? If so, then one might predict that NMDA would actually reduce the precision of matching of the maps by increasing the effective tectal area activated by each visual stimulus. If that were the case, then branches of an ipsilateral unit with a given receptive field could be reinforced not only in the regions with well-correlated retinotectal input from matching field locations but also in surrounding regions where the appropriate visual stimulus would normally fail to activate enough retinotectal axons to open to NMDA channels. However, we do not find any obvious evidence of reduced precision of matching of the ipsilateral maps in the NMDA-treated frogs. There are at least 2 reasons why NMDA treatment could either 
have no net effect or even have a sharpening influence on the maps. First, there is evidence that chronic treatment with NMDA in Rana pipiens tadpoles causes desensitization of NMDA receptors (Debski et al., 1989). Perhaps desensitization occurs in Xenopus as well, canceling out the effect of the added NMDA, with the net result that normal retinotectal input yields normal levels of activation of NMDA receptors. If the desensitization is great enough, then there may even be a net reduction in the effectiveness with which retinotectal input activates NMDA receptors. In that case, a given visual stimulus would activate receptors in a smaller zone of the tectum, thus producing a sharper map than usual. A second, not incompatible, possibility is that NMDA has a disproportionally great effect on inhibitory interneurons of the tectum. In that case, lateral inhibition in the tectum could become relatively stronger with chronic application of NMDA, and each visual event would have a net excitatory effect on a more restricted region of tectum than normal. This alteration in the balance of excitation and inhibition also would have the net effect of sharpening the maps.

Ipsilateral maps which are similar to those in APV-treated frogs are recorded in tecta of dark-reared Xenopus (Keating and Feldman, 1975). As in APV-treated frogs, the ipsilateral maps display recognizable orderliness along the mediolateral tectal axis, with notably poorer order along the rostrocaudal tectal axis. Thus, in both situations, one can deprive growing isthmotectal axons of activity cues from retinotectal axons, in one case by preventing visual input to the tectum and in the other case by decoupling the communication process by blocking NMDA receptors within the tectum.

In contrast to the rather orderly maps we find after treatment with APV, there is major disruption of both the contralateral and ipsilateral maps after treatment with the more powerful NMDA-receptor antagonist, CPP (Davies et al., 1986; Harris et al., 1986). We do not know the cellular basis for this difference. One possibility is that the drug may have had toxic effects, particularly on the parts of the retinotectal projection which originate from the younger, more peripheral parts of the retina or upon the tectal cell targets of these axons. It should be emphasized that all of our recordings in the tectum are from the arbors of retinotectal and isthmotectal axons and not from the tectal cells upon which those axons synapse. Our qualitative assessment of the responses of the retinotectal and isthmotectal units which we recorded in all of our animals leads us to conclude that the various drug treatments did not produce any readily apparent differences in the activity of these inputs to the tectum. However, the responses of the tectal cells under these regimens remain to be examined quantitatively.

In conclusion, we have found that chronic treatment of developing Xenopus tecta with antagonists of the NMDA-type glutamate receptor blocks the activity-dependent matching of binocular maps, and these results are consistent with the hypothesis that activation of these receptors normally plays a pivotal role in the stabilization of appropriately located isthmotectal terminals during development.

\section{References}

Beazley, L., M. J. Keating, and R. M. Gaze (1972) The appearance during development of responses in the optic tectum following visual stimulation of the ipsilateral eye in Xenopus laevis. Vis. Res. 12: 407410.

Cline, H. T., E. A. Debski, and M. Constantine-Paton (1987) N-methyl-D-aspartate receptor antagonist desegregates eye-specific stripes. Proc. Natl. Acad. Sci. USA 84: 4342-4345.
Collingridge, G. L., and T. V. P. Bliss (1987) NMDA receptors-Their role in long-term potentiation. Trends Neurosci. 10: 288-293.

Collingridge, G. L., S. J. Kehl, and H. McLennan (1983) Excitatory amino acids in synaptic transmission in the Schaffer collateral-commissural pathway of the rat hippocampus. J. Physiol. (Lond.) 334: 33-46.

Connor, J. A., W. J. Waldman, P. E. Hockberger, and R. K. S. Wong (1988) Sustained dendritic gradients of $\mathrm{Ca}^{2+}$ induced by excitatory amino acids in CA1 hippocampal neurons. Science 240: 649-653.

Davies, J., R. H. Evans, P. L. Herring, A. W. Jones, H. J. Olverman, P. Pook, and J. C. Watkins (1986) CPP: A new potent and selective NMDA antagonist. Depression of central neuron responses, affinity for $\left[{ }^{3} \mathrm{H}\right]$ D-APV binding sites on brain membranes and anticonvulsant activity. Brain Res. 382: 169-173.

Debski, E. A., and M. Constantine-Paton (1988) The effects of glutamate receptor agonists and antagonists on the evoked tectal potential in Rana pipiens. Soc. Neurosci. Abstr. 14: 674.

Debski, E. A., H. T. Cline, and M. Constantine-Paton (1989) Chronic application of NMDA or APV affects the NMDA sensitivity of the evoked tectal response in Rana pipiens. Soc. Neurosci. Abstr. 15: 495.

Desan, P. H., E. R. Gruberg, K. M. Grewell, and F. Eckenstein (1987) Cholinergic innervation of the optic tectum in the frog Rana pipiens. Brain Res. 413: 344-349.

Dowben, R. M., and J. E. Rose (1953) A metal-filled microelectrode. Science 118: 22-24.

Gaze, R. M., M. J. Keating, G. Székely, and L. Beazley (1970) Binocular interaction in the formation of specific intertectal neuronal connexions. Proc. R. Soc. London [Biol.] 175: 107-147.

Gaze, R. M., M. J. Keating, A. Östberg, and S.-H. Chung (1979) The relationship between retinal and tectal growth in larval Xenopus: Implications for the development of the retino-tectal projection. J. Embryol. Exp. Morphol. 53: 103-143.

Glasser, S., and D. Ingle (1978) The nucleus isthmus as a relay station in the ipsilateral visual projection to the frog's optic tectum. Brain Res. 159: 214-218.

Grant, S. (1982) The Development and Modification of Binocular Neuronal Connections in Xenopus laevis. Ph.D. dissertation, University of London.

Grant, S., and M. J. Keating (1986) Normal maturation involves systematic changes in binocular visual connections in Xenopus laevis. Nature 322: 258-261.

Grobstein, P., and C. Comer (1983) The nucleus isthmi as an intertectal relay for the ipsilateral oculotectal projection in the frog, Rana pipiens. J. Comp. Neurol. 217: 54-74.

Gruberg, E. R., and S. B. Udin (1978) Topographic projections between the nucleus isthmi and the tectum of the frog Rana pipiens. $J$. Comp. Neurol. 179: 487-500.

Harris, E. W., A. H. Ganong, and C. W. Cotman (1984) Long-term potentiation in the hippocampus involves activation of N-methyl-Daspartate receptors. Brain Res. 323: 132-137.

Harris, E. W., A. H. Ganong, D. T. Monaghan, J. C. Watkins, and C. W. Cotman (1986) Action of CPP: A new and highly potent antagonist of N-methyl-D-aspartate receptors in the hippocampus. Brain Res. 382: 174-177.

Hebb, D. O. (1949) The Organization of Behavior, Wiley, New York.

Keating, M. J., and J. Feldman (1975) Visual deprivation and intertectal neuronal connections in Xenopus laevis. Proc. R. Soc. London [Biol.] 191: 467-474.

Keating, M. J., and C. Kennard (1987) Visual experience and the maturation of the ipsilateral visuotectal projection in Xenopus laevis. Neuroscience 21: 519-528.

Keating, M. J., S. Grant, E. A. Dawes, and K. Nanchahal (1986) Visual deprivation and the maturation of the retinotectal projection in Xenopus laevis. J. Embryol. Exp. Morphol. 91: 101-115.

Kleinschmidt, A., M. F. Bear, and W. Singer (1987) Blockage of "NMDA" receptors disrupts experience-dependent plasticity of kitten striate cortex. Science 238: 355-358.

MacDermott, A. B., M. L. Mayer, G. L. Westbrook, S. J. Smith, and J. L. Barker (1986) NMDA-receptor activation increases cytoplasmic calcium concentration in cultured spinal cord neurones. Nature 321: 519-522.

Nieuwkoop, P. D., and J. A. Faber (1967) Normal Table of Xenopus (Daudin), 2nd ed., North Holland, Amsterdam.

Nowak, L., P. Bregestovski, P. Ascher, A. Hebert, and A. Prochiantz 
(1984) Magnesium gates glutamate-activated channels in mouse central neurones. Nature 307: 462-465.

O'Rourke, N. A., and S. E. Fraser (1986) Dynamic aspects of retinotectal map formation revealed by a vital-dye fiber-tracing technique. Dev. Biol. 114: 265-276.

Ricciuti, A. J., and E. R. Gruberg (1985) Nucleus isthmi provides most tectal choline acetyltransferase in the frog $R$. pipiens. Brain Res. 341: 399-402.

Roberts, P. J., and R. A. Yates (1976) Tectal deafferentation in the frog: Selective loss of L-glutamate and $\gamma$-aminobutyrate. Neuroscience $1: 371-374$.

Scherer, W. J., and S. B. Udin (1988) The role of NMDA receptors in the development of binocular maps in Xenopus tectum. Soc. Neurosci. Abstr. 14: 675.

Sperry, R. W. (1944) Optic nerve regeneration with return of vision in anurans. J. Neurophysiol. 7: 57-69.
Udin, S. B. (1983) Abnormal visual input leads to development of abnormal axon trajectories in frogs. Nature 301: 336-338.

Udin, S. B. (1985) The role of visual experience in the formation of binucular projections in frogs. Cell. Mol. Neurobiol. 5: 85-102.

Udin, S. B. (1989) The development of the nucleus isthmi in Xenopus. II. Branching patterns of contralaterally projecting isthmotectal axons during maturation of binocular maps. Vis. Neurosci. 2: 153-163.

Udin, S. B., and M. D. Fisher (1983) Visualization of HRP-filled axons in unsectioned, flattened optic tectum. J. Neurosci. Methods 9: 283285.

Udin, S. B., and M. J. Keating (1981) Plasticity in a central nervous pathway in Xenopus: Anatomical changes in the isthmotectal projection after larval eye rotation. J. Comp. Neurol. 203: 575-594. 